\title{
Surveillance of congenital rubella in Great Britain, 1971-96
}

\author{
Pat A Tookey, Catherine S Peckham
}

Before rubella vaccine was introduced for schoolgirls and susceptible women in 1970, 200-300 babies were born annually in England and Wales with congenital defects associated with maternal rubella. In 1988 the combined measles, mumps, and rubella vaccine was introduced for all 1 year olds; in 1994, to help avert a predicted measles epidemic, all 5-16 year olds were offered combined measles and rubella vaccine. The schoolgirl immunisation programme has now ceased, but antenatal screening continues, with postpartum vaccination for susceptible women. We report the findings from the national congenital rubella surveillance programme from 1971 to 1996.

\section{Methods and results}

Births of babies with congenital rubella have been monitored through the national programme since 1971, with active surveillance through the British Paediatric Surveillance Unit since $1990 .^{1}$ The Office for National Statistics records terminations associated with rubella. Reports of such births and terminations have fallen from an average 48 births and 742 terminations annually in $1971-5$ to four and nine respectively in 1991-5 (figure). In 1996, however, after a resurgence of rubella infection in the community, 12 births and nine terminations were reported.

In 1991-5 only 4 of 19 mothers of children with reported congenital rubella had been born in Britain; none of these reported vaccination, though three should have been offered it previously. Five women had acquired infection abroad (Bangladesh, India, Pakistan, Thailand, Republic of Ireland) before entering Britain in late pregnancy, and a sixth on holiday in Poland. Another five women had been in Britain less than two years at delivery.

In contrast, in 1996 only 2 of 12 mothers acquired infection abroad, one in Bangladesh and the other (born in Britain) on holiday in Spain. Three of the 10 women who acquired infection in Britain were born abroad but

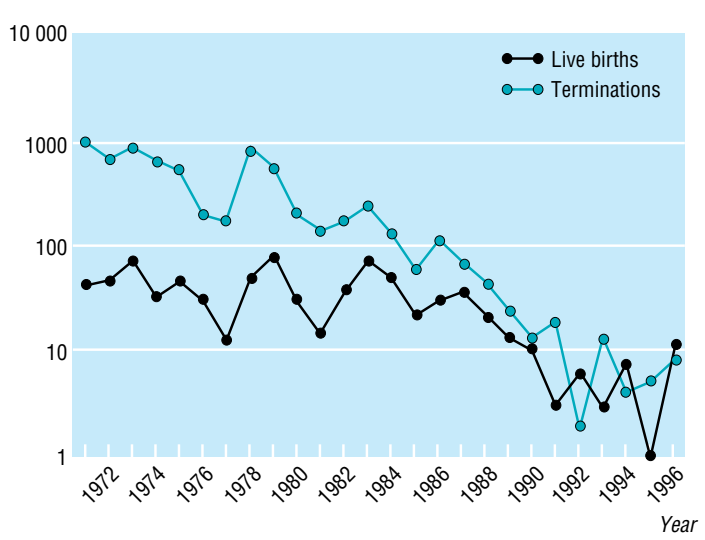

Births of babies with congenital rubella (England, Scotland, and Wales) and terminations associated with rubella disease or contact (England and Wales only), 1971-96 were not recent arrivals. All eight women born in Britain were primigravidas and had been eligible for schoolgirl vaccination. Three women reported previous vaccination-in one, rubella reinfection was confirmed. ${ }^{2}$

At least 20/31 mothers registered with the programme in 1991-6 had symptomatic rubella infection in pregnancy; eight of these were diagnosed and opted to continue to term. Four women reported symptoms antenatally, but infection was not diagnosed; four reported symptoms retrospectively, and in four it was unclear when symptoms were reported or what action was taken.

Before 1991 about $40 \%$ of babies with congenital rubella had typical heart or eye defects, compared with over $80 \%$ since then. Rubella IgG antibodies in young children with otherwise unexplained sensorineural hearing loss used to suggest congenital rubella, but as most now have vaccine induced antibodies, hearing loss without other defects due to congenital rubella may be underdiagnosed.

\section{Comment}

The decline in reports of congenital rubella has resulted in a higher proportion of cases associated with infection acquired abroad or occurring in women with previous vaccination or infection (neither of which confers absolute protection). Immigrant women are more susceptible than the indigenous population; targeting them for immunisation may be appropriate.

The increased incidence of rubella in spring 1996-concentrated in young men who had never been offered vaccination-was followed by an increase in congenital rubella, with all but one baby (whose mother acquired infection abroad) born between the end of July and mid-October. Uptake of the measles, mumps, and rubella vaccine has declined since 1995 (with the largest decrease in 1997- $8^{3}$ ) because of public anxiety about vaccine safety. ${ }^{4}$ If high uptake is not maintained, rubella could once again circulate among young children. Women and health professionals must be aware of the potentially devastating effects of rubella infection. An "immune" result after routine antenatal testing does not preclude recent or current infection, and all pregnant women with suspected symptoms or exposure in the first four months of pregnancy should be offered diagnostic investigation. ${ }^{5}$

We thank colleagues at the Public Health Laboratory Service who support and advise the national congenital rubella surveillance programme, particularly those who are responsible for rubella serosurveillance and for the COVER/Körner programmes; paediatricians who have notified cases; the British Paediatric Surveillance Unit; general practitioners; Sense-the National Deafblind and Rubella Association; colleagues at the Institute of Child Health, Scottish Centre for Infection and Environmental Health, and the Office for National Statistics; and everyone else who has contributed to the surveillance programme over many years.

Contributors: PAT runs the national congenital rubella surveillance programme and wrote the paper. CSP was instrumental in setting up the surveillance programme, supported PAT, commented on the paper, and is the guarantor.
Department of Epidemiology and Public Health, Institute of Child Health, London WC1N 1EH

Pat A Tookey, coordinator of national congenital rubella surveillance programme

Catherine S Peckham,

professor

Correspondence to: Ms Tookey ptookey@ich.ucl.ac.uk

BMJ 1999;318:769-70 
Funding: The national congenital rubella surveillance programme was originally funded by the Medical Research Council and is currently funded by the Public Health Laboratory Service. The British Paediatric Surveillance Unit of the Royal College of Paediatrics and Child Health was supported by the Medical Research Fund of Children Nationwide at the time of the study.

Competing interests: None declared.

1 Hall SM, Nicoll A. The British Paediatric Surveillance Unit-a pioneering method for investigating the less common disorders of childhood. Child Care Health Dev 1998;24:129-43. (Report of a seminar held in June 1995.)

2 Thomas HIJ. Specific antibody avidity studies in clinical microbiology: past, present and future. PHLS Microbiology Digest 1995;12(2):97-102.

3 Sentinel surveillance shows small decline in MMR coverage. Commun Dis Rep CDR Wkly 1998;8(36):317,320.

4 Begg N, Ramsay M, White J, Bozoky Z. Media dents confidence in MMR vaccine. $B M J$ 1998;316:56.

5 Department of Health, Welsh Office, Scottish Office Department of Health, DHSS (Northern Ireland). Immunisation against infectious disease. London: HMSO, 1996.

(Accepted 28 October 1998)

\title{
Cohort study of bacterial species causing urinary tract infection and urinary tract abnormalities in children
}

\author{
Olli Honkinen, Olli-Pekka Lehtonen, Olli Ruuskanen, Pentti Huovinen, Jussi Mertsola
}

Department of

Paediatrics, Turku

University Hospital,

20520 Turku,

Finland

Olli Honkinen,

research fellow

Olli Ruuskanen,

professor

Jussi Mertsola,

consultant in

paediatric infectious

diseases

Laboratory of

Clinical

Microbiology, Turku

University Hospital

Olli-Pekka

Lehtonen,

laboratory director

National Public

Health Institute,

Turku Department,

Turku, Finland

Pentti Huovinen,

laboratory director

Correspondence to: Dr Mertsola

jussi.mertsola@utu.fi

BMJ 1999;318:770-1
Children with urinary tract infection often have anatomical or functional abnormalities in their urinary tract. Imaging studies are therefore recommended, especially for young children, after the first urinary tract infection. ${ }^{1-3}$ There is, however, considerable variation in clinical practice and some resistance to diagnostic imaging for childhood urinary tract infection. ${ }^{4}$ We conducted this study to find out whether an association exists between the bacterial species causing the first urinary tract infection and abnormal findings in subsequent imaging studies.

\section{Patients, methods, and results}

We examined retrospectively the hospital records of all children with a positive urine culture from a sample obtained by suprapubic aspiration (any growth) or catheterisation (growth of at least $10^{3}$ colony forming units/ml) during January 1980 to December 1994. Asymptomatic children and those who had been in hospital for more than 2 days before the specimen was obtained were excluded. Children with proved infection had intravenous pyelography (1980-3) or ultrasonography (1984-94) plus voiding cystourethrography (radiographic in boys and nuclear in girls) 1-2 months after the acute infection.
We identified 1237 positive urine samples. Of these, $942(76 \%)$ were obtained by suprapubic aspiration and $295(24 \%)$ by bladder catheterisation. There were 982 (79\%) cultures positive for Escherichia coli, 66 (5.3\%) for Enterococcus sp, 55 (4.4\%) for Klebsiella sp, $47(3.8 \%)$ for coagulase negative staphylococcus, 39 (3.2\%) for Proteus sp, and 48 for other species. Of the 207 patients with enterococcal, klebsiella, coagulase negative staphylococcal, or proteus infections, hospital records were available for 201 . Forty one patients were excluded (20 had asymptomatic bacteruria, seven had chronic urinary problems such as neurogenic bladder, and in 14 cases one or both of the urinary tract imaging studies were lacking). The urinary tract infection was the first in 92 of the remaining 160 children with infections other than $E$ coli.

We compared the results of these children with those of 92 age and sex matched children whose first urinary tract infection was caused by $E$ coli. Student's $t$ test was used to compare the mean serum $\mathrm{C}$ reactive protein values in the two groups. The frequency of abnormalities in the urinary tract was compared by Pearson's $\chi^{2}$ test or Fisher's exact test if the number of expected observations was five or less in at least one cell.

Age, sex, imaging results, and operations in children according to cause of first urinary tract infection. Values are numbers (percentages) unless stated otherwise

\begin{tabular}{|c|c|c|c|c|c|}
\hline & E coli & Proteus & Klebsiella & Enterococcus & $\begin{array}{l}\text { Coagulase negative } \\
\text { staphylococcus }\end{array}$ \\
\hline No of patients & 92 & 26 & 26 & 26 & 14 \\
\hline Age <2 years (boys/girls) & $39 / 19$ & $12 / 2$ & $12 / 7$ & $11 / 8$ & $4 / 2$ \\
\hline Aged $\geqslant 2$ years (boys/girls) & $17 / 17$ & $7 / 5$ & $3 / 4$ & $6 / 1$ & $1 / 7$ \\
\hline Mean (SD) C reactive protein $(\mathrm{mg} / \mathrm{l})$ & $\begin{array}{l}69(47) \\
(\mathrm{n}=74)\end{array}$ & $\begin{array}{c}23(24)^{\star \star \star} \\
\quad(n=16)\end{array}$ & $\begin{array}{l}83(62) \\
(n=16)\end{array}$ & $\begin{array}{l}88(66) \\
(\mathrm{n}=23)\end{array}$ & $\begin{array}{c}39(53) \\
(n=9)\end{array}$ \\
\hline Reflux & $30(33)$ & $2(8)^{*}$ & $16(62)^{\star \star *}$ & $16(62)^{\star *}$ & $5(36)$ \\
\hline Grade $1-3$ & 26 & $1^{\text {** }}$ & 9 & 9 & 3 \\
\hline Grade 4-5 & 4 & 1 & $7^{* *}$ & $7^{\star *}$ & 2 \\
\hline Obstruction & $1(1)$ & 0 & $4(15)^{\star \star}$ & $3(12)^{\star}$ & $2(14)^{\star}$ \\
\hline Other anatomical abnormalities $\dagger$ & $4(4)$ & 0 & $2(8)$ & 0 & $1(7)$ \\
\hline Children with abnormalitiesł & $32(35)$ & $2(8)^{* *}$ & $18(69)^{* *}$ & $17(65)^{\star *}$ & $6(43)$ \\
\hline Operation or injection therapy for reflux & $7(8)$ & $2(8)$ & $10(38)^{\star \star \star *}$ & $12(46)^{\star \star \star}$ & $5(36)^{\star *}$ \\
\hline
\end{tabular}

${ }^{*} \mathrm{P}<0.05,{ }^{* *} \mathrm{P}<0.01,{ }^{* * *} \mathrm{P}<0.001$ compared with $E$ coli infections.

†These patients had ureter duplex, except patient with staphylococcus who had a polycystic kidney.

‡Some patients had both vesicoureteral reflux and other anatomical abnormalities. 